九州大学学術情報リポジトリ

Kyushu University Institutional Repository

\title{
地域に在住する認知症の人の家族介護者のエンパワ メント尺度の開発
}

坂梨，左織

ht tp://hdl. hand le. net/2324/4060021

出版情報：Kyushu University，2019，博士（看護学），課程博士 バージョン：

権利関係 : 


\title{
Development of the Empowerment Scale for Family Caregivers
}

\section{of Community-Dwelling People with Dementia in Japan}

\begin{abstract}
Aim: This study aimed to develop the empowerment scale for family caregivers of community-dwelling people with dementia (PWD) in Japan (EFCD) and t to validate the scale.
\end{abstract}

Methods: The questionnaires were mailed to 820 family caregivers of PWD. The first version of the EFCD based on interviews with family caregivers and elderly care specialists and content validity results was tested. Participants also completed the Revised Scale for Caregiving Self-Efficacy and the General Health Questionnaire. For the EFCD development procedure, construct validity was evaluated by item analysis and exploratory factor analysis. Criterion validity was tested using Spearman's correlations between scores of the three scales. Reliability was evaluated using Cronbach's alpha, intraclass correlation coefficients (ICC), and the Bland and Altman analysis. The final model was verified by confirmatory factor analysis.

Results: Data from 304 family caregivers were analyzed. Exploratory factor analysis identified a 16-item, four-factor structure for the final version of the EFCD, as follows: 1) Excellent Practice in Dementia Care, 2) Understanding the Essence of Dementia Care, 3) Caring for Oneself as well as for the Person with Dementia, and 4) Having Peers with Shared 
Support Activities. Reliability and validity of the scale was established using the methods described.

Conclusions: The developed EFCD is a reliable and valid measure that provides a simple assessment of empowerment among family caregivers of PWD.

Keywords: dementia, empowerment, family caregiver, reliability and validity, scale development 


\section{Development of the Empowerment Scale for Family Caregivers of Community-Dwelling People with Dementia in Japan}

\section{Introduction}

In 2017, the World Health Organization estimated that about 50 million people worldwide had dementia, and suggested that the condition is now an international public health priority (World Health Organization, 2017). Japan has the highest rate of population aging in the world (United Nations World Population Prospects, 2017) and the number of people with dementia (PWD) is rapidly increasing (Cabinet Office, Government of Japan, 2016). In East Asia, historically, family members are expected to provide care for other family members (Morioka \& Mochizuki, 1997). Indeed, Japanese people tend to solve their family problems by themselves (Kumagai, 2016). The family caregivers of PWD can feel depressed, confused, and distressed by the memory impairment and intense behavioral and psychological symptoms of dementia (BPSD) (Maki \& Yamaguchi, 2014; Moreno et al., 2015). It is critical to understand the type of difficulties family caregivers of PWD face in Japan and to provide them with adequate support.

In 1986, empowerment was proposed as a core component of effective decisionmaking about health and autonomy in personal health promotion (World Health Organization, 1986). Empowerment involves controlling health appropriately, drawing out and manifesting a person's inner strength, and results in a zest for living (Anme, 2014). Empowerment of family caregivers has been suggested to reduce their physical and mental burden (Perlick et 
al., 2013) and increase self-efficacy (Mok, Chan, Chan \& Yeung, 2002).

In one concept analysis of empowerment among family caregiver (Sakanashi \& Fujita, 2017a), components such as 'improvement in caregiving capabilities' (Man, 1998;

Nomura et al., 2009), 'positive control of mind and body' (Li et al., 2003; Polgar, 2009 ), and 'constructive relationships with other people surrounding them' (Ducharme et al., 2002;

Shawler, 2006) were proposed. 'Self-efficacy' was indicated as a related concept of empowerment among family caregivers (Sakanashi \& Fujita, 2017a). Self-efficacy is the confidence that one can carry out certain tasks. However, caregiving self-efficacy proposed by Steffen et al. (2002) does not include the component of 'constructive relationships with other people surrounding them' (Ducharme et al., 2002; Shawler, 2006). Thus, the empowerment among family caregivers is different from the concept of caregiving selfefficacy.

A few previous studies in East Asia have reported characteristics of empowerment among family caregivers of PWD (Che, Yeh, \& Wu, 2006; Nomura et al., 2009). For example, Che, Yeh, and $\mathrm{Wu}$ (2006), who reported the empowerment process of family caregivers of PWD, reported that family caregivers faced more chaotic situational changes, more conflict emotional adoptions, and more multiple functional losses compared with caregivers taking care of persons with diseases other than dementia. Their findings illustrate the process of being empowered as overcoming the difficulties and improving their situation. Family caregivers can feel the loss of a relationship with PWD, and so improving the family 
relationship itself can result in empowerment (Nomura et al., 2009). Solving these problems related to BPSD may be one of the characteristics of empowerment among family caregivers of PWD. However, these studies (Che, Yeh, \& Wu, 2006; Nomura et al., 2009) only used qualitative methods to describe the process of empowerment.

In a previous work, we found (Sakanashi \& Fujita, 2016) only two quantitative studies on the empowerment of family caregivers, which were performed with caregivers of patients with traumatic brain injury (Degeneffe, Chan, Dunlap, Man, \& Sung, 2011) and caregivers of patients after acute hospital discharge (Wu, 2008). The study of caregivers for brain injury has developed a scale focused on measuring self-efficacy rather than empowerment. Wu's scale was designed for caregivers of patients in need of assistant with activity of daily living after hospital discharge, and the scale does not include items assessing problems related to BPSD. Therefore, it may not be applicable to family caregivers of PWD. A systematic review highlighted the need for a universal empowerment assessment tool based on local culture, language, and context (Cyril, Smith, \& Renzaho, 2015).

A scale that assesses the level of empowerment among family caregivers of PWD and the effects of intervention therefore needs to be developed. In this study, we developed the empowerment scale for family caregivers of community-dwelling PWD in Japan (EFCD) and validated the scale.

\section{Methods}




\section{Study design}

This scale was developed and evaluated using the scale development guidelines of Clark and Watson (1995) and the COSMIN checklist (Mokkink et al., 2010). Clark and Watson (1995) developed a theory-based guide to psychological test construction. COSMIN (COnsensus-based Standards for the selection of health status Measurement Instruments) involves two steps: a test and a retest.

\section{Setting and participants}

Participants were all family caregivers of community-dwelling PWD who were at least 20 years old. To meet the standards for good methodological quality, we required a sample size of at least seven times the number of questionnaire items and an absolute size of more than 100 (Mokkink et al., 2010). There were 36 items in the first version of the EFCD, so our minimum sample size was 252 participants. In Japan, medical and social work professionals have many opportunities to contact family caregivers of PWD, including at outpatient medical facilities, at homecare facilities, and at self-help groups. Participants were drawn from users of the outpatient department of a university hospital, five homecare support clinics, and 13 homecare facilities in 17 prefectures in Japan. We also recruited participants from 22 self-help groups in 17 prefectures.

\section{Data collection}

A convenience sample of 820 family caregivers of PWD was recruited between April and December 2017. We collected data on family caregivers' demographic characteristics, 
such as sex, age, relationship with the PWD, employment status, duration of caregiving, presence of other family members who helped with caregiving, and presence of other family members who provided advice. We also obtained the following information on the clinical and demographic characteristics of the PWD: sex, age, caregiving required, and dementia type.

The questionnaires were mailed to participants, who were asked to return them by mail. The test and retest were mailed separately. We only needed 100 responses to the retest, so mailing of the retest questionnaire was stopped after 412 participants. This meant that only participants 1 to 412 had the opportunity to return the retest, and only responses received within 1 to 4 weeks of the first test were included (Murakami, 2006; Silva-Junior, Souto, Fisher, \& Griep, 2018). The questionnaires were numbered to match the participants' tests and retests.

\section{Instruments}

Development of the Empowerment Scale for Family Caregivers of Community-Dwelling

\section{People with Dementia in Japan (EFCD) item pool}

In a previous study of experiences of family caregivers of PWD (Sakanashi \& Fujita, 2017b), we conducted semi-structured interviews with family caregivers and elderly care specialists. Interview data were analyzed using qualitative content analysis (Elo \& Kyngäs, 2008). These data were used to generate an item pool of 44 items. 
Then, based on a previous study (Clark \& Watson,1995; Wu, 2007), a four-point

Likert-type scale (0: disagree, 1: somewhat disagree, 2: somewhat agree, 3: strongly agree) was used, whereby higher scores indicate higher levels of empowerment. Three inverted items (item 11, item 13, and item 14) were reverse-scored before computing the total score. Next, face validity was examined by healthcare professionals. Five administrators from the Alzheimer's Association of Japan evaluated the items for appropriateness. During this process, eight items were deleted, so that the first version of the EFCD contained 36 items.

\section{Assessment of criterion validity}

\section{The Japanese version of the Revised Scale for Caregiving Self-Efficacy (J-RSCSE)}

Caregiving self-efficacy is concept related to empowerment among family caregivers (Sakanashi \& Fujita, 2017a). We used the J-RSCSE as a criterion. Reliability of the J-RSCSE was assessed by examining the internal consistency of the 15 items in the Japanese version (Cronbach's alpha coefficient $=0.84-0.88$; Maruo \& Kono, 2014), based on the original English version of the RSCSE (Steffen et al., 2002). The constructs consist of three subscales, as follows: self-efficacy in obtaining respite, self-efficacy in responding to disruptive behaviors, and self-efficacy in controlling upsetting thoughts about caregiving. Each item is measured on a visual analog scale (0-100), whereby higher scores indicate higher levels of self-efficacy. 


\section{The 12-item General Health Questionnaire (Japanese version; GHQ12-J)}

General health was one of the components of empowerment among family caregivers (Sakanashi \& Fujita, 2017a), and the GHQ12-J was used as a criterion. The GHQ12-J was originally used as a screening tool for depression (Goldberg \& Blackwell, 1970) and its reliability and validity have been confirmed (Nakagawa \& Daibo, 2013).

Bimodal scoring is used for each item $(0,0,1,1)$, and higher scores indicate worse mental health.

\section{Data analysis}

Data were analyzed using SPSS version 24.0 and AMOS version 24.0 (IBM SPSS Japan, Tokyo, Japan). Descriptive statistics were used to examine the central tendency of demographic characteristics. To identify items for possible exclusion in the first version of the EFCD, we estimated the standard deviation and means of all items to detect ceiling and floor effects, and examined the correlations between all items. We then used exploratory factor analysis to assess construct validity, with principal axis factoring and promax rotation.

EFCD reliability was also estimated by assessing internal consistency using Cronbach's alpha; values of $\alpha>0.7$ were considered to indicate good consistency (Clark \& Watson, 1995). For criterion validity, we used Spearman's correlation coefficients to assess the correlations of EFCD scores with J-RSCSE and GHQ12-J scores.

Confirmatory factor analysis was used to assess the fit indices of the EFCD model 
obtained using exploratory factor analysis. To assess the fit of the whole EFCD model, the following indices were used: (1) the GFI and the AGFI; (2) the CFI; and (3) the RMSEA. To assess the fit of the partial model, we used the path coefficient for each item $(p<0.001)$.

We examined EFCD reliability using the intraclass correlation coefficient (ICC) for the test and retest scores. In addition, Bland and Altman plots were created to determine the agreement. In these plots, the mean different (d) between the test and retest with corresponding 95\% CI and 95\% limits of agreement (LOA) were presented $(\mathrm{d} \pm \mathrm{tn}-1 \times \mathrm{SDd})$ (Bland, \& Altman, 1986).

\section{Ethical considerations}

All phases of this study were reviewed and approved by the ethical review board of Fukuoka university (ID number 2016M081). Representatives of each facility and institution were informed of the study purpose. The researcher and research collaborators clearly explained the purpose of the study in person, and assured all participants of their anonymity and confidentiality. Participants were clearly informed in writing that their study participation was voluntary and that returning the anonymous self-administered questionnaire would be taken as their consent to participate. Informed consent was obtained from all family caregivers who agreed to participate.

\section{Results}


In total, 307 (37.4\%) of the 820 questionnaires were returned. Three returned questionnaires had at least $50 \%$ of the items missing in the first version of the EFCD, and these were excluded from the analysis, leaving 304 (37.1\%) questionnaires for analysis. The listwise deletion and pairwise deletion methods are notorious for producing biased or inefficient estimates in most situations (Little \& Rubin, 2002). Missing values were assigned the average value of the relevant subscale for each measure (IBM Corporation Knowledge Center, 2016); the percentage of missing values ranged from $0.0 \%-1.97 \%$ in the first version of the EFCD, $0.66 \%-2.96 \%$ in the J-RSCSE, and $1.97 \%-3.62 \%$ in the GHQ12-J. This study met the standard for good methodological quality (Mokkink et al., 2010).

\section{Participant characteristics}

Table 1 shows participant characteristics. About $70 \%$ of family caregivers were female, about half were spouses. Approximately $60 \%$ of PWD were female. Table 1 also summarizes the J-RSCSE and GHQ12-J scores. Using a GHQ12-J cutoff score of 3/4 (Honda, Shibata, \& Nakane, 2001), 59.5\% of family caregivers who had a GHQ12-J score $\geq 4$ also reported depressed.

\section{Item analysis}

Table 2 shows the results of the item analysis for the 36 items of the first version of the EFCD. Mean values ranged from $0.86-2.60$ and standard deviations ranged from $0.66-$ 1.09. Two items were deleted (items 2 and 13) because of a ceiling effect, but no other items showed either a ceiling or floor effect. The total correlation between all items ranged from 
0.32-0.72, with three items deleted (item 4: negative correlation; item 10: no correlation; and item 15: a correlation of approximately 0.2 ). No items showed a correlation $\geq 0.7$ with another item. Finally, 31 items were retained. The correlations between the remaining 31 items ranged from $0.11-0.67$. Normality analysis results showed that the data were normally distributed.

\section{Conceptual structure of the EFCD}

Table 3 shows the results of our exploratory factor analyses. Using principal axis factoring and the promax rotation method for the 31 items, a scree plot indicated a four-factor solution that explained $52.09 \%$ of the total variance. After deleting item factor loadings less than $0.4,16$ items remained. The conceptual structure of the EFCD was explained by 16 items on the four factors. The four factors were Excellent Practice in Dementia Care (items 1, 3, 5, 7, 8, 9, 25, and 35), Understanding the Essence of Dementia Care (items 30, 33, and 34), Caring for Oneself as well as for the Person with Dementia (items 12, 19, and 20), and Having Peers with Shared Support Activities (items 29 and 36). The Spearman correlations between the four factors were all significant $(0.41-0.68)$.

\section{Reliability of the EFCD}

Cronbach's alpha, which measures internal consistency, was 0.90 for the whole EFCD scale, and $>0.7$ for each all of the four factors $(0.70-0.86)$.

\section{Criterion validity of the EFCD}

Table 4 shows the results of criterion validity testing of the EFCD. There were 
moderate associations in the expected directions between the total EFCD and J-RSCSE scores $(\mathrm{r}=0.52, \mathrm{p}<0.01)$, and negative weak associations between the total EFCD and GHQ12-J scores $(\mathrm{r}=-0.27, \mathrm{p}<0.01)$.

\section{Goodness-of-fit indices for the EFCD final model}

Figure 1 shows the goodness-of-fit indices for the final model. Confirmatory factor analysis showed that the fit indices of the EFCD model obtained by exploratory factor analysis were acceptable. The GFI was 0.898 and the AGFI was 0.858 . The CFI was $>0.9$ (0.913). The RMSEA was $<0.08$ (0.076). The path coefficient for each item was appropriate $(0.52-0.82 ; \mathrm{p}<0.001)$

\section{Stability of the EFCD}

Responses for the test-retest comparison (i.e., responses to both questionnaires) were obtained from $101(24.5 \%)$ of the 412 participants who were sent the retest. A total of 80 (19.4\%) participants met the inclusion criteria, with an interval of 7-28 days between the first and second tests (average: $14.2 \pm 4.9$ days). The average participant age was $64.8 \pm 10.7$ years. The ICC was 0.51 for the whole 16 -item scale and ranged from $0.44-0.66$ for the four factors $(\mathrm{p}<0.01)$. For the whole scale with first 36 -items version of the EFCD, the ICC was $0.47(\mathrm{p}<0.01)$. Figure 2 shows Bland and Altman plots; these show that zero was within the $95 \% \mathrm{CI}$ of the mean difference (d) between the test and retest of the EFCD, which indicates that there was no trend/bias. The $95 \%$ LOA was $-0.1 \pm 13.9$.

\section{Discussion}


We developed and validated the EFCD. Confirmatory factor analysis identified the following four factors of empowerment among family caregivers of PWD: 1) Excellent Practice in Dementia Care; 2) Understanding the Essence of Dementia Care; 3) Caring for Oneself as well as for the Person with Dementia; and 4) Having Peers with Shared Support Activities.

Factor 1 and Factor 3 were similar to two of the six concepts proposed in the concept analysis of empowerment among family caregiver (Sakanashi \& Fujita, 2017a), namely, ‘improvement in caregiving capability' (Man, 1998; Nomura et al., 2009) and 'positive control of mind and body' (Li et al., 2003; Polgar, 2009 ), which were critical for empowering family caregivers. Factor 1, 'Excellent Practice in Dementia Care', indicates family caregivers' improvement of their care skill, knowledge, and information about dementia care. Nomura et al. (2009) reported the needs for education to increase the understanding of dementia and the appropriate use of social resources to empower family caregivers. Empowered caregivers understand the medical care that the person is receiving (Polgar, 2009) or actively acquire useful information about healthcare, support, and legal procedures (Shawler, 2006). Factor 3, 'Caring for Oneself as well as for the Person with Dementia', illustrates the situation that family caregivers actively take care of themselves as well as the PWD. Wu (2008) reported that empowered family caregivers paid attention to both care-receivers and themselves. Empowered family caregivers who have good control over their minds and bodies take breaks (Li et al., 2003), seek support (Polgar, 2009), or 
ensure that they take time out for themselves (Degeneffe et al., 2011).

Factor 2, 'Understanding the Essence of Dementia Care', means that the empowered family caregivers of PWD understand how dementia is perceived in society and in the community. Public negative attitudes towards people living with dementia is a social problem (Aihara, et al., 2016). Empowerment includes recognition of public negative attitudes (Dooher \& Byrt, 2008). Thus, the empowerment among family caregivers of PWD need to understand the social problem. Factor 4, 'Having Peers with Shared Support Activities', means that the empowered family caregivers of PWD are actively involved in societal and communal activities. Empowerment itself is multi-faceted; while many studies have focused on individual psychological empowerment, only a few have measured healthcare users' actions (Cyril, Smith, \& Renzaho, 2015). Wu's (2008) scale reported the empowerment at the individual level as a social resources' receiver, while family caregivers need more social participation and community involvement, especially, family caregivers of PWD (Maki \& Yamaguchi, 2014). Empowerment includes 'participation' (Dooher \& Byrt, 2008). Therefore, the empowerment among family caregivers of PWD needs not as a social resources' receiver, but an active attitude such as social participation and community involvement. Factor 2 and Factor 4 have not been included in previous empowerment scales (Degeneffe et al., 2011; Wu, 2008). Factor 4, 'Having Peers with Shared Support Activities' was similar to the result of concept analysis of empowerment among family caregiver, 'constructive relationships with other people surrounding them' (Sakanashi \& Fujita, 2017a). To the best of our 
knowledge, Factor 2, 'Understanding the Essence of Dementia Care' has not been reported.

The cumulative contribution rate of the four factors before rotation was $52.09 \%$. In

social sciences literature, it reported to allow 60 percent or less of the cumulative contribution rate (Hair, Black, Babin, \& Anderson, 2013). The construct validity of the EFCD is therefore acceptable. Using the COSMIN checklist (Mokkink et al., 2010), our results indicated that the EFCD is reliable and valid. Namely, the EFCD had a good internal consistency (Cronbach's alpha was 0.90 for the whole EFCD scale), reliability (the ICC was 0.51 for the whole EFCD scale), construct validity (confirmatory factor analysis showed that the fit indices of the EFCD model were acceptable), and criterion validity (there were moderate associations in the expected directions between the total scores for the EFCD and J-RSCSE, and negative weak associations between the total scores for the EFCD and GHQ12-J).

The EFCD has important applications in the clinical and research arenas. A previous study reported the difficulties in managing multiple data source and analyzing all the data (Nomura et al., 2009). The EFCD may enable researchers to quantitatively assess the level of empowerment and evaluate the effects of intervention. Japan has the world's highest rate of population aging. The EFCD could therefore be particularly useful in East Asia for investigating empowerment of family caregivers in aging populations.

We found that the EFCD has a high internal consistency and moderate stability. Murakami (2006) reported that the average interval between test and retest is, at most, 7-28 days. Empowerment may vary over time in a particular individual (Che, Yeh, \& Wu, 2006), 
so a moderate correlation is indicative of reasonable stability.

This study has several limitations. The response rate of the postal survey was low. However, this rate is comparable to a response rate of $40 \%$ in a large survey of family caregivers in Japan (Fukui, Sakka, Amiya, Sato, \& Kamibeppu, 2018). The association between the EFCD and GHQ12-J scores was low. We used the GHQ12-J, which has been used in previous studies (Perlick et al., 2013; Sakanashi \& Fujita, 2017a). However, previous studies have reported that the GHQ is related to caregiver burden (using the Zarit Burden Interview, ZBI; Baboolal, Davis, Stewart, Ramesar, \& McRae, 2018) and psychological distress of family caregivers (using the Neuropsychiatry Inventory, NPI, and Perceived Stress Scale, PSS; Javadpour, Ahmadzadeh, \& Bahredar, 2009). The GHQ tends to focus on negative concepts, so the use of the GHQ12-J may constitute weak evidence for the criterion validity of the EFCD, as we believe that the EFCD reflects more positive concepts such as self-efficacy. Final version of the EFCD that was tested contained 20 fewer items than the first version of the EFCD. The deleted items of the first version were similar to the items retained the second version. In addition, this may be because the item pool was developed from interviews with empowered family caregivers. The first version of the EFCD may have contained some items that would only apply to family caregivers with high levels of empowerment. Clark and Watson (1995) suggest that researchers perform systematic sampling of all content that is potentially relevant to the target construct. The initial pool should also be broader and more comprehensive than the theoretical view of the target 
construct. The first version of the EFCD embodies this approach to scale development (Clark $\&$ Watson, 1995), but the use of this method may have influenced the item reduction. The cumulative contribution rate might also have affected the construct validity of the EFCD. Finally, the goodness-of-fit might have limited our ability to strengthen the model's fit. Future studies should recruit a more diverse participant sample, and explore acceptability and diagnostic accuracy in other settings.

\section{Conclusion}

The EFCD appears to be a reliable and valid tool to conduct simple assessments of the empowerment of family caregivers of community-dwelling PWD in Japan, the country with the world's highest rate of population aging. The EFCD could also be used to facilitate nursing interventions that encourage empowerment among family caregivers. The assessment criteria may contribute to a better understanding of empowerment among family caregivers of PWD in other countries with aging populations. 


\section{Acknowledgments}

We would like to thank the family caregivers of people with dementia who took part in the study, as well as the staff members at the cooperating institutions. This study was a part of a research project funded by Grants-in-Aid for Scientific Research (KAKENHI) of the Japan Society for Promotion of Science [grant number JP 15K11837] from 2015-2017.

\section{Disclosure}

The authors declare no conflicts of interest with respect to the research, authorship, and/or publication of this article.

\section{Author Contributions}

S.S. contributed to conception and design of the study, data analysis and interpretation, and manuscript drafting. K.F. contributed to the conception of the study, data analysis and interpretation, and critical revision of manuscript for intellectual content. All authors read and approved the final manuscript.

\section{References}

Aihara, Y., Kato, H., Sugiyama, T., Ishi, K., \& Goto, Y. (2016). Public attitudes towards people living with dementia: A cross-sectional study in urban Japan (innovative practice). Dementia, 
1471301216682118. [Epub ahead of print]

Anme, T. (2014). Empowerment science that remains close to the light of life-everyone plays a leading role: A new form of coexistence. Kyoto, Japan: Kitaooji Shobo Publishing. Hiyokuatusyano kyouikugaku [Pedagogy of the oppressed]

Baboolal, N., Davis, G., Stewart, R., Ramesar, J., \& McRae, A. (2018). Comparisons between different elements of reported burden and common mental disorder in caregivers of ethnically diverse people with dementia in Trinidad. PLOS ONE, 13(7), e0201165.

Bland, J. M. \& Altman D. G. (1986). Statistical methods for assessing agreement between two methods of clinical measurement. The Lancet, 327(8476), 307-310.

Cabinet Office, Government of Japan. (2016). Annual report on the aging society. [Cited 6, 2019.] Available from URL: http://www8.cao.go.jp/kourei/whitepaper/w2016/html/gaiyou/s1_2_3.html

Che, H. L., Yeh, M. L., \& Wu, S. M. (2006). The self-empowerment process of primary caregivers: A study of caring for elderly with dementia. The Journal of Nursing Research, 14(3), 209-218.

Clark, L. A. \& Watson, D. (1995). Constructing validity: Basic issues in objective scale development. Psychological Assessment, 7(3), 309-319.

Cyril, S., Smith, B. J., \& Renzaho, M. N. (2015). Systematic review of empowerment measures in health promotion. Health Promotion International, 31(4), 809-826.

Dooher J., Byrt R., Edited by Cutcliffe, J. R., \& McKenna, H. P. (2008). The essential concepts of nursing: An attempt at concept analysis in the field of nursing (C. Yamada, Trans.). Tokyo, 
Japan: Elsevier Japan.

Degeneffe, C. E., Chan, F., Dunlap, L., Man, D., \& Sung, C. (2011). Development and validation of the caregiver empowerment scale: A resource for working with family caregivers of persons with traumatic brain injury. Rehabilitation Psychology, 56(3), 243-250.

Ducharme, F., LéVesque, L., Gendron, L., \& Legault, A. (2002). Development process and qualitative evaluation of a program to promote the mental health of family caregivers. Clinical Nursing Research, 10, 182-201.

Elo, S., \& Kyngäs, H. (2008). The qualitative content analysis process. Journal of Advanced Nursing, 62(1), 107-115.

Fukui, C., Sakka, M., Amiya, R. M., Sato, I., \& Kamibeppu, K. (2018). Validation of family conflict scales for family caregivers of persons with dementia in long-term care facilities and exploration of family conflicts and support. International Psychogeriatrics, 30(5), 749-759.

Goldberg, D. P. \& Blackwell, B. (1970). Psychiatric illness in general practice: A detailed study using a new method of case identification. British Medical Journal, 2(5707), 439-443.

Hair, J. F., Black, W. C., Babin, B. J., \& Anderson, R. E. (2013). Multivariate Date Analysis:

Pearson New International Edition. P.107. Pearson Higher Ed.

Honda, S., Shibata, Y., \& Nakane, Y. (2001). Screening of psychiatric impairment using GHQ-12 Questionnaire. Journal of Health and Welfare Statistics, 48, 5-10.

IBM Corporation Knowledge Center. (2016). SPSS Statistics 24.0.0 missing values. [Cited 6, 2019.] Available from URL: 
https://www.ibm.com/support/knowledgecenter/ja/SSLVMB_24.0.0/spss/mva/intro_missing _ values_option.html

Javadpour, A., Ahmadzadeh, L., \& Bahredar, M. J. (2009). An educative support group for female family caregivers: Impact on caregivers psychological distress and patient's neuropsychiatry symptoms. International Journal of Geriatric Psychiatry, 24(5), 469-471.

Kumagai, F., \&Ishii-Kuntz, M. (2016). Family violencein Japan: a life course perspective. Singapore:Springer.

Li, H., Melnyk, B. M., McCann, R., Chatcheydang, J., Koulouglioti, C., Nichols, L. W., .. . Ghassemi, A. (2003). Creating avenues for relative empowerment (CARE): A pilot test of an intervention to improve outcomes of hospitalized elders and family caregivers. Research Nursing Health, 26(4), 284-299.

Little, R. J. A. \& Rubin, D. B. (2002). Statistical analysis with missing data (2nd ed.). New York, NY: Wiley Interscience.

Maki, Y. \& Yamaguchi, H. (2014). Early detection of dementia in the community under a community-based integrated care system. Geriatrics \& Gerontology International,14, 2-10.

Man, D. W. K. (1998). The empowering of Hong Kong Chinese families with a brain damaged member: Its investigation and measurement. Brain Injury, 12(3), 245-254.

Maruo, S. \& Kono, A. (2014). Effects of a self-efficacy improvement program on care given by family caregivers for behavioral and psychological symptoms of dementia. An Official Journal of the Japan Primary Care Association, 37(2),104-111. 
Mok, E., Chan, F., Chan, V., \& Yeung, E. (2002). Perception of empowerment by family caregivers of patients with a terminal illness in Hong Kong. International Journal of Palliative Nursing, $8(3), 137-145$.

Mokkink, L. B., Terwee, C. B., Patrick, D. L., Alonso, J., Stratford, P. W., Knol, D. L., ... De Vet, H. C. W. (2010). The COSMIN checklist for assessing the methodological quality of studies on measurement properties of health status measurement instruments: An international Delphi study. Quality of Life Research, 19(4), 539-549.

Moreno, J. A., Nicholls, E., Ojeda, N., De los Reyes-Aragón, C. J., Rivera, D., \& Arango-Lasprilla, J. C. (2015). Caregiving in dementia and its impact on psychological functioning and healthrelated quality of life: Findings from a Colombian sample. Journal of Cross-Cultural Gerontology, 30(4), 393-408.

Morioka, K. \& Mochizuki, T. (1997). New family sociology (4th ed). Tokyo, Japan: Baifukan.

Murakami, Y. (2006). How to develop a psychological measure. Kyoto, Japan: Kitaoji Shobou.

Nakagawa, Y. \& Daibo, I. (2013). Japanese version General Health Questionnaires guide (Enhancement Version). Tokyo, Japan: Nihonbunkakagakusya.

Nomura, M., Makimoto, K., Kato, M., Shiba, T., Matsuura, C., Shigenobu, K.,... Ikeda, M. (2009). Empowering older people with early dementia and family caregivers: A participatory action research study. International Journal of Nursing Studies, 46(4), 431-441.

Perlick, D. A., Straits-Troster, K., Strauss, J. L., Norell, D., Tupler, L. A., Levine, B., .. Dyck, D. G. (2013). Implementation of multifamily group treatment for veterans with traumatic brain 
injury. Psychiatric Services, 64(6), 534-540.

Polgar, M. (2009). How are people empowered to help a homeless relative? Human Organization, $68,431-438$.

Sakanashi, S. \& Fujita, K. (2016). Literature review on empowerment of family caregivers. The 36th Annual Conference of Japan academy of Nursing Science, Tokyo.

Sakanashi, S. \& Fujita, K. (2017a). Empowerment of family caregivers of adults and elderly persons: A concept analysis. International Journal of Nursing Practice, 23(5), e12573.

Sakanashi, S. \& Fujita, K. (2017b). Empowerment structure of family caregivers of persons with dementia. Poster session presented at the 20th East Asian Forum of Nursing Scholars, Hong Kong.

Shawler, C. (2006). The empowerment of older mothers and daughters: Rehabilitation strategies following a hip fracture. Geriatric Nursing, 27(6), 371-377.

Silva-Junior, J. S., Souto, E. P., Fischer, F. M., \& Griep, R. H. (2018). Validity and test-retest reliability of the Brazilian version of the Return-to-work self-efficacy questionnaire. Revista de Saude Pública, 52, 65.

Steffen, A. M., McKibbin, C., Zeiss, A. M., Gallagher-Thompson, D., \& Bandura, A. (2002). The revised scale for caregiving self-efficacy: Reliability and validity studies. The Journals of Gerontology. Series B: Psychological Sciences and Social Sciences, 57(1), 74-86.

United Nations World Population Prospects. (2017). World population prospects (2017 revision). [Cited 6, 2019.] Available from URL: 
https://www.un.org/development/desa/publications/world-population-prospects-the-2017-

revision.html

World Health Organization. (1986). The Ottawa Charter for Health Promotion 1986. [Cited 6, 2019.]

Available from URL: http://www.who.int/healthpromotion/conferences/previous/ottawa/en/.

World Health Organization. (2017). Dementia: Number of people affected to triple in next 30 years.

[Cited 6, 2019.] Available from URL: https://www.who.int/news-room/detail/07-12-2017-

dementia-number-of-people-affected-to-triple-in-next-30-years

Wu, X. (2007). Content validity and translation validity for measurement of main care-givers'

empowerment in China: Focusing on the maintenance and improvement of daily life

activities of elder care-receivers. Journal of Japan Academy of Nursing Science, 27, 23-33.

Wu, X. (2008). Chinese version "Main care-givers empowerment measurement (MCEM)." Journal of Japan Academy of Nursing Science, 28, 3-13. 
Table 1

Clinical and demographic characteristics of family caregivers and people with dementia $(N=304)$

\begin{tabular}{|c|c|}
\hline Characteristics & Values \\
\hline \multicolumn{2}{|l|}{ Family caregivers } \\
\hline \multicolumn{2}{|l|}{ Sex, n (\%) } \\
\hline Female & $208(68.4 \%)$ \\
\hline Male & $92(30.3 \%)$ \\
\hline Missing & $4(1.3 \%)$ \\
\hline Age (years), mean $\pm \mathrm{SD}$ & $65.27 \pm 12.06$ \\
\hline \multicolumn{2}{|c|}{ Relationship with person with dementia, $\mathrm{n}(\%)$} \\
\hline Spouse & $137(45.1 \%)$ \\
\hline Daughter/Son & $119(39.1 \%)$ \\
\hline Daughter-in-law & $29(9.5 \%)$ \\
\hline Others & $13(4.3 \%)$ \\
\hline Missing & $6(2.0 \%)$ \\
\hline \multicolumn{2}{|l|}{ Employment status } \\
\hline Not working/retired & $185(60.9 \%)$ \\
\hline Employed part-time & $58(19.1 \%)$ \\
\hline Employed full-time & $48(15.8 \%)$ \\
\hline Missing & $13(4.3 \%)$ \\
\hline \multicolumn{2}{|l|}{ Duration of caregiving } \\
\hline$\leq 1$ year & $46(15.1 \%)$ \\
\hline$>1-5$ years & $134(44.0 \%)$ \\
\hline$>5-10$ years & $82(27.0 \%)$ \\
\hline$>10$ years & $27(8.9 \%)$ \\
\hline Missing & $15(4.9 \%)$ \\
\hline \multicolumn{2}{|c|}{ Family members helping with caregiving } \\
\hline Yes & $215(70.7 \%)$ \\
\hline No & $83(27.3 \%)$ \\
\hline Missing & $5(2.0 \%)$ \\
\hline \multicolumn{2}{|c|}{ Family members providing advice } \\
\hline Yes & $253(83.2 \%)$ \\
\hline No & $46(15.1 \%)$ \\
\hline Missing & $5(1.6 \%)$ \\
\hline \multicolumn{2}{|l|}{ People with dementia } \\
\hline \multicolumn{2}{|l|}{ Sex, n $(\%)$} \\
\hline Female & $189(62.2 \%)$ \\
\hline Male & $108(35.5 \%)$ \\
\hline Missing & $7(2.3 \%)$ \\
\hline Age (years), mean $\pm \mathrm{SD}$ & $80.42 \pm 8.84$ \\
\hline \multicolumn{2}{|l|}{ Caregiving required } \\
\hline Mild & $102(33.6 \%)$ \\
\hline Moderate & $107(35.2 \%)$ \\
\hline Severe & $61(20.1 \%)$ \\
\hline Not rated & $15(4.9 \%)$ \\
\hline Unknown & $11(3.6 \%)$ \\
\hline Missing & $8(2.6 \%)$ \\
\hline
\end{tabular}


Type of dementia

Alzheimer type

$181(59.5 \%)$

Dementia with Lewy bodies

$36(11.8 \%)$

Vascular dementia

$14(4.6 \%)$

Frontotemporal dementia

$11(3.6 \%)$

Unknown

$46(15.1 \%)$

Missing

$16(5.3 \%)$

Japanese version of the Revised Scale for Caregiving Self-Efficacy $(0-1500)$

Total

$744.83 \pm 300.15(80-1500)$

SE-OR

$44.12 \pm 30.19(0-100)$

SE-RDPB

$55.35 \pm 26.30(0-100)$

SE-CUT

$50.13 \pm 22.61(0-100)$

Japanese General Health Questionnaire 12 (0-12)

Total

$5.20 \pm 3.84(0-12)$

Factor1 (Item 2,5,6,9,10,11)

$0.48 \pm 0.34(0-1)$

Factor2 (Item 1,3,4,7,8,12)

$0.39 \pm 0.34(0-1)$

Abbreviations: SE-OR: Self-efficacy for obtaining respite; SE-RDPB: Self-efficacy for responding to disruptive behaviors; SE-CUT: Self-efficacy for controlling upsetting thoughts about caregiving; SD: standard deviation. 
Table 2

Item analysis for the Empowerment Scale for Family Caregivers of Community-Dwelling People with Dementia $(N=304)$

\begin{tabular}{|c|c|c|c|c|c|c|}
\hline $\begin{array}{l}\text { Item } \\
\text { no. }\end{array}$ & & Mean \pm SD & $\begin{array}{l}\text { Ceiling } \\
\text { effect }\end{array}$ & $\begin{array}{l}\text { Floor } \\
\text { effect }\end{array}$ & $\begin{array}{c}\text { I-T } \\
\text { correlation } \\
\text { analysis }\end{array}$ & $\begin{array}{l}\text { Interitem } \\
\text { correlation }\end{array}$ \\
\hline 1 & I understand about symptoms of dementia. & $2.32 \pm 0.71$ & 3.02 & 1.61 & $.53^{* *}$ & $-0.16-0.55$ \\
\hline $2^{\ddagger}$ & $\begin{array}{l}\text { I understand that people with dementia sometimes have delusions that they are being robbed, and may } \\
\text { loiter. }\end{array}$ & $2.60 \pm 0.66$ & 3.26 & 1.94 & $.46^{* *}$ & $0.13-0.55$ \\
\hline 3 & I proactively collect knowledge or information about dementia and caregiving. & $2.11 \pm 0.79$ & 2.90 & 1.32 & $.63^{* *}$ & $0.11-0.52$ \\
\hline $4^{*}$ & I have things that I still don't understand about dementia and providing care. & $1.86 \pm 0.73$ & 2.60 & 1.13 & $-.23 * *$ & $-0.29-0.23$ \\
\hline 5 & I understand the importance of ensuring the independence and safety of the person with dementia. & $2.38 \pm 0.67$ & 3.05 & 1.70 & $.59^{* *}$ & $-0.12-0.47$ \\
\hline 6 & I consider issues from the perspective of the person with dementia. & $1.95 \pm 0.71$ & 2.67 & 1.24 & $.61^{* *}$ & $-0.20-0.47$ \\
\hline 7 & I encourage the independence of the person with dementia. & $1.91 \pm 0.77$ & 2.69 & 1.14 & $.52^{* *}$ & $-0.16-0.43$ \\
\hline 8 & I have mastered caregiving for the person with dementia. & $1.47 \pm 0.77$ & 2.24 & 0.70 & $.69^{* *}$ & $-0.24-0.64$ \\
\hline 9 & I can manage changes in the physical symptoms of the person with dementia. & $1.59 \pm 0.76$ & 2.34 & 0.83 & $.68^{* *}$ & $-0.24-0.64$ \\
\hline $10^{\ddagger}$ & I cannot manage every aspect of caregiving for the person with dementia. & $1.84 \pm 0.79$ & 2.63 & 1.04 & -0.04 & $-0.32-0.23$ \\
\hline 11 & I cannot accept the person with dementia. ${ }^{\dagger}$ & $1.99 \pm 0.89$ & 2.88 & 1.10 & $.44^{* *}$ & $-0.25-0.39$ \\
\hline 12 & It is beneficial to me to care for the person with dementia. & $1.84 \pm 0.87$ & 2.71 & 0.97 & $.52^{* *}$ & $-0.13-0.50$ \\
\hline $13^{\star}$ & I hide the person with dementia from other people. ${ }^{\dagger}$ & $2.40 \pm 0.85$ & 3.24 & 1.55 & $.40^{* *}$ & $-0.20-0.36$ \\
\hline 14 & My mental condition is unstable because of the person with dementia. ${ }^{\dagger}$ & $1.46 \pm 0.94$ & 2.38 & 0.54 & $.38^{* *}$ & $-0.27-0.39$ \\
\hline $15^{\star}$ & I clarify home-care limits. & $1.36 \pm 0.94$ & 2.29 & 0.42 & $.14^{*}$ & $-0.20--0.21$ \\
\hline 16 & I intend to keep providing care until the end. & $1.90 \pm 0.94$ & 2.85 & 0.96 & $.41^{* *}$ & $-0.12--0.34$ \\
\hline 17 & I can predict the future disease process of the person with dementia. & $1.44 \pm 0.90$ & 2.33 & 0.54 & $.43^{* *}$ & $-0.20-0.41$ \\
\hline 18 & I value not only the person with dementia, but also my life and future. & $2.05 \pm 0.83$ & 2.88 & 1.22 & $.32^{* *}$ & $0.12-0.29$ \\
\hline
\end{tabular}




\begin{tabular}{lllll}
$2.10 \pm 0.73$ & 2.83 & 1.36 & $.60^{* *}$ & $-0.12-0.58$ \\
$2.04 \pm 0.69$ & 2.73 & 1.35 & $.58^{* *}$ & $-0.13-0.58$ \\
$1.69 \pm 0.82$ & 2.51 & 0.87 & $.41^{* *}$ & $-0.18-0.33$ \\
$2.11 \pm 0.93$ & 3.04 & 1.18 & $.34^{* *}$ & $-0.13-0.41$ \\
$1.21 \pm 0.92$ & 2.13 & 0.29 & $.51^{* *}$ & $-0.20-0.44$ \\
$1.58 \pm 0.78$ & 2.37 & 0.80 & $.36^{* *}$ & $0.12-0.31$ \\
$1.03 \pm 0.81$ & 1.84 & 0.22 & $.63^{* *}$ & $-0.29-0.56$ \\
$1.62 \pm 0.79$ & 2.41 & 0.83 & $.70^{* *}$ & $-0.25-0.57$ \\
$1.72 \pm 0.95$ & 2.67 & 0.77 & $.55^{* *}$ & $-0.20-0.47$ \\
$1.93 \pm 1.01$ & 2.93 & 0.92 & $.38^{* *}$ & $0.13-0.37$ \\
$1.47 \pm 1.09$ & 2.55 & 0.38 & $.59^{* *}$ & $0.13-0.53$ \\
$2.13 \pm 0.72$ & 2.85 & 1.41 & $.64^{* *}$ & $-0.18-0.53$ \\
$1.81 \pm 0.87$ & 2.68 & 0.95 & $.67^{* *}$ & $0.18-0.53$ \\
$1.82 \pm 0.85$ & 2.66 & 0.97 & $.56^{* *}$ & $-0.17-0.46$ \\
$1.83 \pm 0.69$ & 2.51 & 1.14 & $.61^{* *}$ & $-0.20-0.67$ \\
$1.65 \pm 0.76$ & 2.42 & 0.89 & $.61^{* *}$ & $-0.22-0.67$ \\
$1.68 \pm 0.77$ & 2.46 & 0.91 & $.72^{* *}$ & $-0.24-0.59$ \\
$0.86 \pm 1.04$ & 1.90 & -0.18 & $.56^{* *}$ & $-0.16-0.53$ \\
\hline
\end{tabular}

Note. ${ }^{\dagger}$ Reverse-scored item

${ }^{\ddagger}$ Deleted item ${ }^{* *} \mathrm{p}<0.01$

Abbreviations: SD: standard deviation; I-T correlation analysis: item-total correlation analysis. 
Table 3

Factor analysis of the Empowerment Scale for Family Caregivers of Community-Dwelling People with Dementia $(N=304)$

\begin{tabular}{|c|c|c|c|c|c|c|c|}
\hline $\begin{array}{l}\text { Item } \\
\text { no. }\end{array}$ & \multicolumn{2}{|l|}{ Item } & Factor 1 & Factor 2 & Factor 3 & Factor 4 & Communality \\
\hline \multicolumn{2}{|c|}{ Factor 1 Excellent Practice in Dementia Care } & \multicolumn{2}{|l|}{$\alpha^{\dagger}=0.86$} & \multirow[b]{2}{*}{-0.16} & \multirow[b]{2}{*}{-0.07} & \multirow[b]{2}{*}{0.22} & \multirow[b]{2}{*}{0.64} \\
\hline 8 & I have mastered caregiving for the person with dementia. & & 0.80 & & & & \\
\hline 9 & \multicolumn{2}{|l|}{ I can manage changes in the physical symptoms of the person with dementia. } & 0.79 & 0.03 & -0.11 & 0.03 & 0.60 \\
\hline 1 & \multicolumn{2}{|l|}{ I have an understanding about the symptoms of dementia. } & 0.64 & 0.13 & 0.06 & -0.27 & 0.41 \\
\hline 7 & \multicolumn{2}{|l|}{ I encourage the independence of the person with dementia. } & 0.54 & -0.04 & 0.08 & -0.04 & 0.29 \\
\hline 3 & \multicolumn{2}{|l|}{ I proactively collect knowledge or information about dementia and caregiving. } & 0.50 & 0.21 & 0.12 & -0.11 & 0.46 \\
\hline 5 & \multicolumn{2}{|l|}{$\begin{array}{l}\text { I understand the importance of ensuring the independence and safety of the person with } \\
\text { dementia. }\end{array}$} & 0.44 & 0.13 & 0.30 & -0.10 & 0.47 \\
\hline 25 & \multicolumn{2}{|l|}{ I address caregiving with confidence. } & 0.43 & -0.15 & 0.12 & 0.32 & 0.41 \\
\hline 35 & \multicolumn{2}{|l|}{$\begin{array}{l}\text { I have my own opinions about the societal, medical care, and welfare issues that surround } \\
\text { dementia. }\end{array}$} & 0.41 & 0.33 & -0.09 & 0.25 & 0.64 \\
\hline \multicolumn{2}{|r|}{ Factor 2 Understanding the Essence of Dementia Care } & \multicolumn{3}{|l|}{$\alpha=0.80$} & & & \\
\hline 33 & I understand social trends and public perception toward dementia. & & -0.04 & 0.88 & 0.00 & -0.02 & 0.72 \\
\hline 34 & I understand the problems of the society or community that surrounds dementia. & & 0.07 & 0.69 & -0.10 & 0.15 & 0.62 \\
\hline 30 & I accept that other caregivers have different situations. & & 0.03 & 0.46 & 0.11 & 0.21 & 0.47 \\
\hline \multicolumn{2}{|r|}{ Factor 3 Caring for Oneself as well as for the Person with Dementia } & \multirow[t]{4}{*}{$\alpha=0.72$} & & & & & \\
\hline 19 & I have a loving and grateful relationship with the person with dementia. & & -0.01 & -0.07 & 0.89 & 0.03 & 0.74 \\
\hline 20 & I examine and appraise the quality of my caregiving and make improvements. & & 0.06 & 0.17 & 0.54 & -0.02 & 0.45 \\
\hline 12 & It is beneficial to me to care for the person with dementia. & & 0.03 & -0.10 & 0.51 & 0.22 & 0.35 \\
\hline \multicolumn{2}{|r|}{ Factor 4 Having Peers with Shared Support Activities } & \multirow[t]{3}{*}{$\alpha=0.70$} & & & & & \\
\hline 29 & I have peers supporting me. & & -0.24 & 0.13 & 0.10 & 0.76 & 0.56 \\
\hline \multirow[t]{5}{*}{36} & I am involved with activities for people with dementia and their family caregivers. & & & 0.05 & 0.01 & 0.61 & 0.51 \\
\hline & \begin{tabular}{|l} 
Factor Correlations \\
\end{tabular} & Factor 1 & 1.00 & 0.68 & 0.56 & 0.60 & \\
\hline & & Factor 2 & & 1.00 & 0.49 & 0.55 & \\
\hline & & Factor 3 & & & 1.00 & 0.41 & \\
\hline & & Factor 4 & & & & 1.00 & \\
\hline
\end{tabular}

Note. ${ }^{\dagger} \alpha$ : Cronbach's alpha. 
Table 4

Correlations of the Empowerment Scale for Family Caregivers of Community-Dwelling People with Dementia with the Japanese version of the Revised Scale for Caregiving Self-Efficacy and the 12-item General Health Questionnaire 12, Japanese version $(N=304)$

\begin{tabular}{|c|c|c|c|c|c|}
\hline & \multicolumn{5}{|c|}{ Empowerment of Family Caregivers of People with Dementia } \\
\hline & Overall & $\begin{array}{l}\text { Excellent Practice } \\
\text { in Dementia Care }\end{array}$ & $\begin{array}{l}\text { Understanding } \\
\text { the Essence } \\
\text { of Dementia Care }\end{array}$ & $\begin{array}{l}\text { Caring for Oneself as } \\
\text { well as for the Person } \\
\text { with Dementia }\end{array}$ & $\begin{array}{l}\text { Having Peers with } \\
\text { Shared Support } \\
\text { Activities }\end{array}$ \\
\hline J-RSCSE & $0.522^{* *}$ & $0.482^{* *}$ & $0.381^{* *}$ & $0.449^{* *}$ & $0.478^{* *}$ \\
\hline Self-efficacy for obtaining respite & $0.218^{* *}$ & $0.184^{* *}$ & $0.147^{*}$ & $0.142^{*}$ & $0.256^{* *}$ \\
\hline Self-efficacy for responding to disruptive behaviors & $0.532^{* *}$ & $0.517^{* *}$ & $0.395^{* *}$ & $0.476^{* *}$ & $0.442^{* *}$ \\
\hline $\begin{array}{l}\text { Self-efficacy for controlling upsetting thoughts about } \\
\text { caregiving }\end{array}$ & $0.430^{* *}$ & $0.404^{* *}$ & $0.307^{* *}$ & $0.416^{* *}$ & $0.374^{* *}$ \\
\hline GHQ12-J & $-0.265^{* *}$ & $-0.222^{* *}$ & $-0.155^{* *}$ & $-0.244^{* *}$ & $-0.243^{* *}$ \\
\hline Factor 1 & $-0.227^{* *}$ & $-0.193^{* *}$ & $-0.140^{*}$ & $-0.193^{* *}$ & $-0.198^{* *}$ \\
\hline Factor 2 & $-0.297^{* *}$ & $-0.248^{* *}$ & $-0.175^{* *}$ & $-0.283^{* *}$ & $-0.279^{* *}$ \\
\hline
\end{tabular}

Abbreviations: J-RSCSE: Japanese version of the Revised Scale for Caregiving Self-Efficacy; GHQ12-J: General Health Questionnaire 12, Japanese version. 


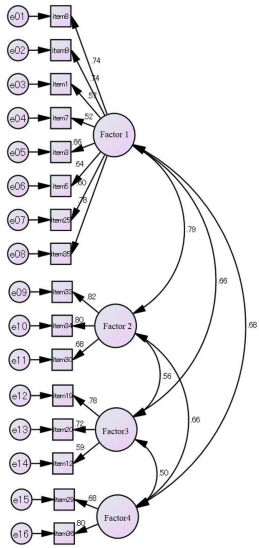

GFI -0.898

$\mathrm{AGFI}=0.858$

CFI -0.913

RMSEA $=0.076$ 


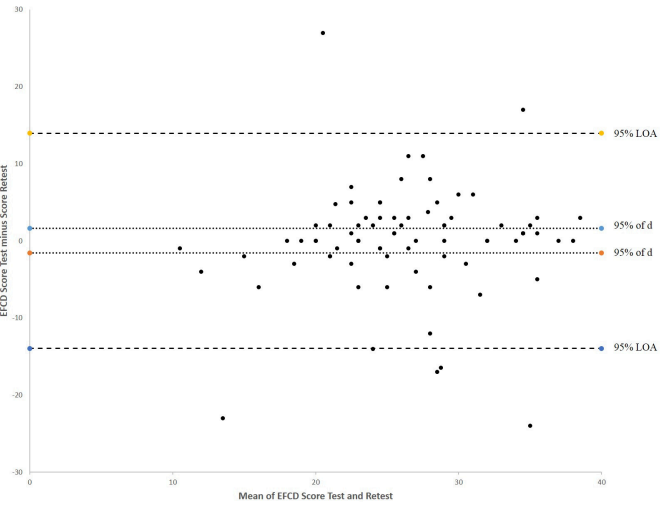

